\title{
A Randomized Study of Endobronchial Valves for Advanced Emphysema
}

\author{
Frank C. Sciurba, M.D., Armin Ernst, M.D., Felix J.F. Herth, M.D., \\ Charlie Strange, M.D., Gerard J. Criner, M.D., Charles H. Marquette, M.D., Ph.D., \\ Kevin L. Kovitz, M.D., M.B.A., Richard P. Chiacchierini, Ph.D., \\ Jonathan Goldin, M.D., Ph.D., and Geoffrey McLennan, M.D., Ph.D., \\ for the VENT Study Research Group*
}

\section{BACKGROUND}

Endobronchial valves that allow air to escape from a pulmonary lobe but not enter it can induce a reduction in lobar volume that may thereby improve lung function and exercise tolerance in patients with pulmonary hyperinflation related to advanced emphysema.

\section{METHODS}

We compared the safety and efficacy of endobronchial-valve therapy in patients with heterogeneous emphysema versus standard medical care. Efficacy end points were percent changes in the forced expiratory volume in 1 second $\left(\mathrm{FEV}_{1}\right)$ and the 6-minute walk test on intention-to-treat analysis. We assessed safety on the basis of the rate of a composite of six major complications.

\section{RESULTS}

Of 321 enrolled patients, 220 were randomly assigned to receive endobronchial valves (EBV group) and 101 to receive standard medical care (control group). At 6 months, there was an increase of $4.3 \%$ in the $\mathrm{FEV}_{1}$ in the EBV group (an increase of 1.0 percentage point in the percent of the predicted value), as compared with a decrease of $2.5 \%$ in the control group (a decrease of 0.9 percentage point in the percent of the predicted value). Thus, there was a mean between-group difference of $6.8 \%$ in the $\mathrm{FEV}_{1}(\mathrm{P}=0.005)$. Roughly similar between-group differences were observed for the 6-minute walk test. At 12 months, the rate of the complications composite was $10.3 \%$ in the EBV group versus $4.6 \%$ in the control group $(\mathrm{P}=0.17)$. At 90 days, in the EBV group, as compared with the control group, there were increased rates of exacerbation of chronic obstructive pulmonary disease (COPD) requiring hospitalization $(7.9 \%$ vs. $1.1 \%, \mathrm{P}=0.03)$ and hemoptysis $(6.1 \%$ vs. $0 \%$, $\mathrm{P}=0.01$ ). The rate of pneumonia in the target lobe in the EBV group was $4.2 \%$ at 12 months. Greater radiographic evidence of emphysema heterogeneity and fissure completeness was associated with an enhanced response to treatment.

\section{CONCLUSIONS}

Endobronchial-valve treatment for advanced heterogeneous emphysema induced modest improvements in lung function, exercise tolerance, and symptoms at the cost of more frequent exacerbations of COPD, pneumonia, and hemoptysis after implantation. (Funded by Pulmonx; ClinicalTrials.gov number, NCT00129584.)

From the University of Pittsburgh School of Medicine, Pittsburgh (F.C.S.); Beth Israel Deaconess Medical Center, Harvard Medical School, Boston (A.E.); University of Heidelberg, Heidelberg, Germany (F.J.F.H.); the Medical University of South Carolina, Charleston (C.S.); Temple University School of Medicine, Philadelphia (G.J.C.); University Hospital of Nice, Nice, France (C.H.M.); Tulane University Health Sciences Center, New Orleans (K.L.K.); Chiacchierini and Associates, Rockville, MD (R.P.C.); David Geffen School of Medicine at UCLA, Los Angeles (J.G.); and the University of lowa, lowa City (G.M.). Address reprint requests to Dr. Sciurba at the University of Pittsburgh, 3471 Fifth Ave., Suite 1211, Kaufmann Bldg., Pittsburgh, PA 15213, or at sciurbafc@ upmc.edu.

* Members of the Endobronchial Valve for Emphysema Palliation Trial (VENT) study research group are listed in the Supplementary Appendix, available with the full text of this article at NEJM.org.

N Engl J Med 2010;363:1233-44 Copyright (๑) 2010 Massachusetts Medical Society. 
E MPHYSEMA IS A LEADING CAUSE OF DISability and death. Lung-volume-reduction surgery, in which selected areas of hyperinflated lungs are resected, improves exercise tolerance and prolongs life in selected patients. However, concern regarding the risk of perioperative death and complications contributes to underutilization. $^{1-4}$ Less invasive bronchoscopic techniques that are based on the presumed physiological effects of lung-volume-reduction surgery have been developed.5-10 Early uncontrolled trials using unidirectional valves placed in selected lung airways to block regional inflation while allowing exhalation have reported improvements in lung function and symptoms with modest risk, including distal pneumonia or pneumothorax. ${ }^{5,6,9,11-13}$

In this randomized, prospective, multicenter study, called the Endobronchial Valve for Emphysema Palliation Trial (VENT), we sought to determine the safety and efficacy of unilateral treatment with endobronchial valves, as compared with standard medical care, in improving coprimary outcome measures of expiratory flow and walk distance in patients with advanced emphysema.

\section{METHODS}

\section{PATIENTS}

From December 2004 through April 2006, we screened 977 patients at 31 centers in the United States. Of these patients, 321 were enrolled and randomly assigned in a 2:1 ratio to receive therapy with a Zephyr endobronchial valve (Emphasys Medical [now Pulmonx]) (EBV group with 220 patients) or standard medical care (control group with 101 patients). ${ }^{14}$ The two study groups were well matched except for a slightly higher mean partial pressure of carbon dioxide $\left(\mathrm{PaCO}_{2}\right)$ in the arterial blood in the control group $(1.1 \mathrm{~mm} \mathrm{Hg}$, $\mathrm{P}=0.04$ ) (Table 1). All patients provided written informed consent before screening.

Eligibility criteria included an age of 40 to 75 years, a diagnosis of heterogeneous emphysema, a forced expiratory volume in one second $\left(\mathrm{FEV}_{1}\right)$ of 15 to $45 \%$ of the predicted value, a total lung capacity of more than $100 \%$ of the predicted value, a residual volume of more than $150 \%$ of the predicted value, a body-mass index (the weight in kilograms divided by the square of the height in meters) of 31.1 or less for men or 32.3 or less for women, a $\mathrm{PaCO}_{2}$ of less than $50 \mathrm{~mm} \mathrm{Hg}$ and a partial pressure of oxygen $\left(\mathrm{PaO}_{2}\right)$ of more than $45 \mathrm{~mm} \mathrm{Hg}$ (while breathing ambient air), and a post-rehabilitation 6-minute walk distance of at least $140 \mathrm{~m}$ (459 ft). Exclusion criteria included a carbon monoxide diffusing capacity of less than $20 \%$ of the predicted value, the presence of giant bullae or $\alpha_{1}$-antitrypsin deficiency, previous thoracotomy, excessive sputum, severe pulmonary hypertension, active infection, or unstable cardiac conditions.

\section{STUDY DESIGN}

Before randomization, patients underwent 6 to 8 weeks of pulmonary rehabilitation and optimized medical management at the discretion of the treating physician within the context of the Global Initiative for Chronic Obstructive Lung Disease (GOLD) guidelines. We obtained quantitative and visual indexes of the severity of lobar emphysema and fissure integrity, using multirowdetector high-resolution computed tomography (HRCT) to determine eligibility, optimal selection criteria, and mechanistic outcome measures. ${ }^{15-17}$ All images were then analyzed at a core laboratory. We chose not to use a sham procedure, given the imposed risk to the control group without potential benefit. ${ }^{18-20}$ Additional details about the methodology are provided in the Supplementary Appendix, available with the full text of this article at NEJM.org. The study was conducted in accordance with the protocol, which is also available at NEJM.org.

\section{OUTCOME MEASURES}

The coprimary effectiveness end points were the percent change in the $\mathrm{FEV}_{1}$ and distance on the 6-minute walk test in the EBV group, as compared with the control group, at 6 months after randomization. The primary safety end point was the difference in the rate of a composite of six major complications at 6 months. This composite consisted of death, empyema, massive hemoptysis, pneumonia distal to valves, pneumothorax or air leak of more than 7 days' duration, or ventilator-dependent respiratory failure for more than 24 hours' duration. (For a complete list of adverse events, see Table S1 in the Supplementary Appendix.)

Secondary efficacy end points were mean changes in patients' quality of life, as measured on the St. George's Respiratory Questionnaire 


\begin{tabular}{|c|c|c|c|}
\hline Variable & $\begin{array}{l}\text { Endobronchial- } \\
\text { Valve Therapy } \\
\qquad(\mathrm{N}=220)\end{array}$ & $\begin{array}{l}\text { Control } \\
(\mathrm{N}=101)\end{array}$ & P Value \\
\hline \multicolumn{4}{|l|}{ Demographic characteristic } \\
\hline Age $-\mathrm{yr}$ & $65.34 \pm 6.83$ & $64.91 \pm 5.84$ & 0.56 \\
\hline Male sex — no. (\%) & $133(60.4)$ & $49(48.5)$ & 0.05 \\
\hline White race - no. $(\%) \dagger$ & $213(96.8)$ & $99(98.0)$ & 1.00 \\
\hline Body-mass index & $25.09 \pm 3.96$ & $24.82 \pm 3.39$ & 0.51 \\
\hline \multicolumn{4}{|l|}{ Smoking history } \\
\hline Ever smoked — no. (\%) & $219(99.6)$ & $99(98.0)$ & 0.23 \\
\hline Years of smoking & $37.74 \pm 8.95$ & $36.12 \pm 8.62$ & 0.17 \\
\hline No. of pack-yr & $63.29 \pm 29.58$ & $61.67 \pm 30.33$ & 0.64 \\
\hline Receiving continuous oxygen - no./total no. (\%) & $65 / 148(43.9)$ & $30 / 72(41.7)$ & 0.77 \\
\hline \multicolumn{4}{|l|}{ Medication use } \\
\hline Short-acting bronchodilator only — no. (\%) & $17(7.7)$ & $9(8.9)$ & 0.83 \\
\hline Long-acting bronchodilator only - no. (\%)』 & $42(19.1)$ & $21(20.8)$ & 0.77 \\
\hline Long-acting bronchodilator and inhaled glucocorticoid only — no. (\%) $\mathbb{S}$ & $60(27.3)$ & $29(28.7)$ & 0.90 \\
\hline $\begin{array}{l}\text { Long-acting beta agonist, inhaled glucocorticoid, and long-acting } \\
\text { anticholinergic agent only - no. (\%) }\end{array}$ & $101(45.9)$ & $42(41.6)$ & 0.67 \\
\hline Any oral glucocorticoid — no. (\%) & $28(12.7)$ & $13(12.9)$ & 0.97 \\
\hline \multicolumn{4}{|l|}{ Arterial blood gas $\emptyset$} \\
\hline $\mathrm{PaO}_{2}-\mathrm{mm} \mathrm{Hg}$ & $69.14 \pm 10.26$ & $68.44 \pm 8.09$ & 0.51 \\
\hline $\mathrm{PaCO}_{2}-\mathrm{mm} \mathrm{Hg}$ & $40.53 \pm 4.25$ & $41.61 \pm 4.82$ & 0.04 \\
\hline \multicolumn{4}{|l|}{ Lung function } \\
\hline \multicolumn{4}{|l|}{$\mathrm{FEV}_{1}$} \\
\hline Value - liters & $0.87 \pm 0.26$ & $0.84 \pm 0.25$ & 0.32 \\
\hline Percent of predicted value & $30 \pm 8$ & $30 \pm 8$ & 1.00 \\
\hline \multicolumn{4}{|l|}{ Forced vital capacity } \\
\hline Value - liters & $2.71 \pm 0.78$ & $2.62 \pm 0.82$ & 0.28 \\
\hline Percent of predicted value & $70 \pm 15$ & $70 \pm 16$ & 0.92 \\
\hline \multicolumn{4}{|l|}{ Carbon monoxide diffusing capacity } \\
\hline Value - $\mathrm{ml}$ carbon monoxide $/ \mathrm{min} / \mathrm{mm} \mathrm{Hg}$ & $9.52 \pm 3.11$ & $10.15 \pm 5.69$ & 0.68 \\
\hline Percent of predicted value & $33 \pm 9$ & $36 \pm 16$ & 0.11 \\
\hline \multicolumn{4}{|l|}{ Residual volume } \\
\hline Value - liters & $4.79 \pm 1.15$ & $4.63 \pm 1.20$ & 0.16 \\
\hline Percent of predicted value & $216 \pm 44$ & $212 \pm 47$ & 0.28 \\
\hline \multicolumn{4}{|l|}{ Total lung capacity } \\
\hline Value - liters & $7.60 \pm 1.44$ & $7.37 \pm 1.55$ & 0.12 \\
\hline Percent of predicted value & $124 \pm 15$ & $125 \pm 16$ & 0.62 \\
\hline \multicolumn{4}{|l|}{ Exercise performance } \\
\hline Distance on 6-minute walk test $-\mathrm{m}$ & $333.9 \pm 87.4$ & $350.9 \pm 83.2$ & 0.15 \\
\hline Cycle ergometry peak workload - W & $45.0 \pm 23.9$ & $43.2 \pm 21.3$ & 0.71 \\
\hline
\end{tabular}

* Plus-minus values are means $\pm \mathrm{SD}$. $\mathrm{FEV}_{1}$ denotes forced expiratory volume in 1 second, $\mathrm{PaO}_{2}$ partial pressure of oxygen, and $\mathrm{PaCO}_{2}$ partial pressure of carbon dioxide.

$\uparrow$ Race was self-reported.

The body-mass index is the weight in kilograms divided by the square of the height in meters.

$\int$ Long-acting bronchodilator includes either a long-acting anticholinergic agent or a beta-agonist.

q Measurements were performed while the patient was breathing ambient air.

The New England Journal of Medicine 
(SGRQ), which ranges from 0 to 100 , with a higher score indicating a worse quality of life; incremental cycle exercise capacity; dyspnea, as measured on the Modified Medical Research Council scale, ranging from 0 to 4 , with a higher score indicating more severe dyspnea; and daily oxygen use. The magnitude of heterogeneity as a continuous variable and other prespecified variables, such as fissure completeness, were tested in a multivariate model as possible predictors of response.

\section{DEFINITION OF EMPHYSEMA HETEROGENEITY AND LUNG-SEGMENT TARGETING BY HRCT}

We used a semiautomated, computer-based quantitative analysis of HRCT scans to target the endobronchial-valve treatment (for details, see the Supplementary Appendix). The percentage of heterogeneity was defined as the difference in the quantitative emphysema score (proportion of pixels of less than -910 Hounsfield units) between the targeted lobe and the ipsilateral adjacent nontargeted lobe. ${ }^{21}$ This percentage was then converted to a Likert scale, with a score of 1 for 1 to $25 \%, 2$ for 26 to $50 \%, 3$ for 51 to $75 \%$, and 4 for 76 to $100 \%$. A 1-unit difference between treated and untreated lobes was required for inclusion in the analyses. We targeted the lobe with the highest percentage of emphysema and the greatest degree of heterogeneity. Fissure integrity was defined as the completeness of the fissure (more than $90 \%$ of the fissure present on thinslice HRCT) on at least one axis (sagittal, axial, or coronal views), as classified by the consensus of two independent readers at the HRCT core laboratory.

\section{PROCEDURE AND FOLLOW-UP}

A flexible bronchoscope with or without rigid bronchoscopy was used for valve implantation. Antibiotics (second- or third-generation cephalosporin or fluoroquinolone) were given intravenously before the procedure, for 24 hours after the procedure, and then orally for 7 days. The type of anesthesia was decided according to the local protocol. Valves were placed unilaterally in lobar, segmental, or subsegmental bronchi on the basis of individual anatomy to completely isolate the targeted lobe (Fig. S1 and S2 in the Supplementary Appendix). Follow-up data (including vital signs, review of adverse events, and radiographic evidence of atelectasis) were collected on the first day, between 2 and 3 days, and between
7 and 10 days and then at 30,90,180, and 365 days (outcome measures and review of adverse events). Standardized HRCT was performed at baseline and at 6 months.

\section{STUDY OVERSIGHT}

The design and conduct of the trial, analysis of the data, and decision to submit the manuscript for publication involved an executive committee consisting of investigators, a statistician paid by the study sponsor, and representatives of the sponsor. The authors wrote the manuscript, including the first draft. The study was approved by each center's institutional review board and conducted under the observation of an independent data and safety monitoring board. An independent clinical events committee reviewed and adjudicated all adverse events. All members of the writing committee take responsibility for the completeness and accuracy of all data presented. A safety-related stopping rule that was established by the data and safety monitoring board was a rate of death in the EBV group at 30 or 90 days after endobronchial-valve therapy that exceeded the rate in the surgical group of the National Emphysema Treatment Trial (ClinicalTrials.gov number, NCT00000606). ${ }^{2}$

\section{STATISTICAL ANALYSIS}

We prespecified all data analyses in a formal statistical analysis plan, which is available in the Supplementary Appendix. On the basis of levels observed in pilot studies, we determined the number of patients who would be needed to provide a power of $90 \%$ to detect a mean improvement of $15 \%$ in the $\mathrm{FEV}_{1}$ in the EBV group, as compared with the control group, at 6 months and a mean improvement of $17 \%$ in distance on the 6-minute walk test at 6 months, assuming an alpha level of 0.05 . Success was defined in the intention-to-treat analysis for both primary outcome measures, with a P value of less than 0.05 indicating statistical significance on a two-sided test. The primary safety end point was met if the upper limit of the $95 \%$ confidence interval for the between-group difference in the rate of the complications composite was less than $30 \%$. Missing data for the primary outcomes were assigned on the basis of criteria that are described in detail in the Supplementary Appendix or imputed by regression imputation on the basis of patients' baseline factors.

The analysis plan was devised to identify po- 
tential key outcome predictors and mechanisms of improvement. We used a mixed linear model procedure with SAS software (PROC MIXED) to evaluate the effect of predefined covariates on dependent outcome variables. ${ }^{22,23}$ Additional univariate subgroup analyses were performed with the use of the independent variables that remained as interactions in the mixed model.

\section{RESULTS}

\section{PATIENTS}

At 12 months, the rate of loss to follow-up was higher among patients in the control group $(20.8 \%)$ than in the EBV group $(11.8 \%, \mathrm{P}=0.04)$. Of the 321 patients who underwent randomization, 42 of 220 in the EBV group (19.1\%) and 28 of 101 in the control group (27.7\%) had missing data for the primary efficacy end point, requiring imputation of the value at the 6-month analysis. Of these 70 patients, 6 died, 4 were too ill for follow-up, and 60 declined to participate in followup or missed the specified window (Fig. 1).

\section{PROCEDURAL DETAILS}

Among all patients, moderate sedation was used in $71.5 \%$ and general anesthesia in $28.5 \%$. Flexible bronchoscopy was used alone (in $98.6 \%$ of the patients) or in combination with rigid bronchoscopy. The mean number of valves placed was 3.8 per patient (range, 1 to 9). The mean ( \pm SD) duration of the procedure was $33.8 \pm 20.5$ minutes. The right upper lobe was targeted in a majority of patients $(52.3 \%)$, followed by the left upper lobe (in $24.3 \%$ ), the left lower lobe (in $14.0 \%$ ), and the right lower lobe (in 9.3\%). The rate of compliance with the antibiotic protocol was $98.1 \%$.

\section{PRIMARY AND SECONDARY EFFICACY OUTCOMES}

At 6 months, the $\mathrm{FEV}_{1}$ increased by $4.3 \%(95 \%$ confidence interval [CI], 1.4 to 7.2 ) in the EBV group, an absolute increase of 1.0 percentage point (95\% CI, 0.2 to 1.8$)$ of the predicted value, and decreased by $2.5 \%$ (95\% CI, -5.4 to 0.4$)$ in the control group, a drop of 0.9 percentage point ( $95 \%$ CI, -1.7 to -0.1 ) in the percent of the predicted value. Thus, there was a mean betweengroup difference in $\mathrm{FEV}_{1}$ of $6.8 \%$ (95\% CI, 2.1 to 11.5; $\mathrm{P}=0.005$ ) (Table 2).

At 6 months, the distance traveled in the 6-minute walk test increased by $2.5 \%$ (95\% CI, -1.1 to 6.1) in the EBV group and decreased by $3.2 \%$ ( $95 \% \mathrm{CI},-8.9$ to 2.4 ) in the control group, for a mean between-group difference of $5.8 \%$ (95\% CI, 0.5 to 11.2; $\mathrm{P}=0.04$ ). This represented an increase of $9.3 \mathrm{~m}$ ( $95 \% \mathrm{CI},-0.5$ to 19.1$)$ in the EBV group, as compared with a decrease of $10.7 \mathrm{~m}$ (95\% CI, -29.6 to 8.1 ) in the control group $(\mathrm{P}=0.02)$. There were modest changes in all secondary end points (scores on the SGRQ and Modified Medical Research Council scale, average daily oxygen use, and maximum workload by cycle ergometry) (Table 2). Additional subgroup analyses, response analyses, and exploratory analyses of lung volumes and BODE index (which includes the body-mass index, the degree of airflow obstruction and dyspnea, and exercise capacity) are available in the Supplementary Appendix.

\section{ADVERSE EVENTS}

By 6 months, the rate of the composite of six major complications was $6.1 \%$ in the EBV group and $1.2 \%$ in the control group $(\mathrm{P}=0.08)$, a level that met the prespecified primary safety criteria, since the between-group difference was $4.9 \%$ (95\% CI, 1.0 to 8.8 ) with an upper limit of the $95 \%$ confidence interval that was less than a prespecified difference of $30 \%$.

A Cox regression analysis determined that no covariates independently influenced the rate of the complications composite by 6 months and that endobronchial-valve therapy was not significantly associated with the complications composite at 6 months $(P=0.14)$. In follow-up from 6 to 12 months, the rate of the complications composite among patients in the EBV group (4.7\%) was similar to that in the control group (4.6\%), resulting in an overall rate at 12 months of $10.3 \%$ in the EBV group and $4.6 \%$ in the control group $(\mathrm{P}=0.17)$. Among the adverse events at 6 months were six deaths $(2.8 \%)$ in the EBV group, as compared with no deaths in the control group $(\mathrm{P}=0.19)$. Cause of death included respiratory failure not associated with the EBV procedure (in three patients), cancer (in one), ischemic colitis (in one), and massive hemoptysis (in one). The rates of death from any cause by 12 months were similar in the two groups: $3.7 \%$ in the EBV group and $3.5 \%$ in the control group $(\mathrm{P}=0.88$ by the log-rank test). A multivariate Cox regression analysis for survival through 12 months showed no significant between-group difference $(\mathrm{P}=0.48)$. The most common adverse event in the EBV group at 12 months was pneumonia distal to the valves in nine patients (4.2\%). All pneumonias 


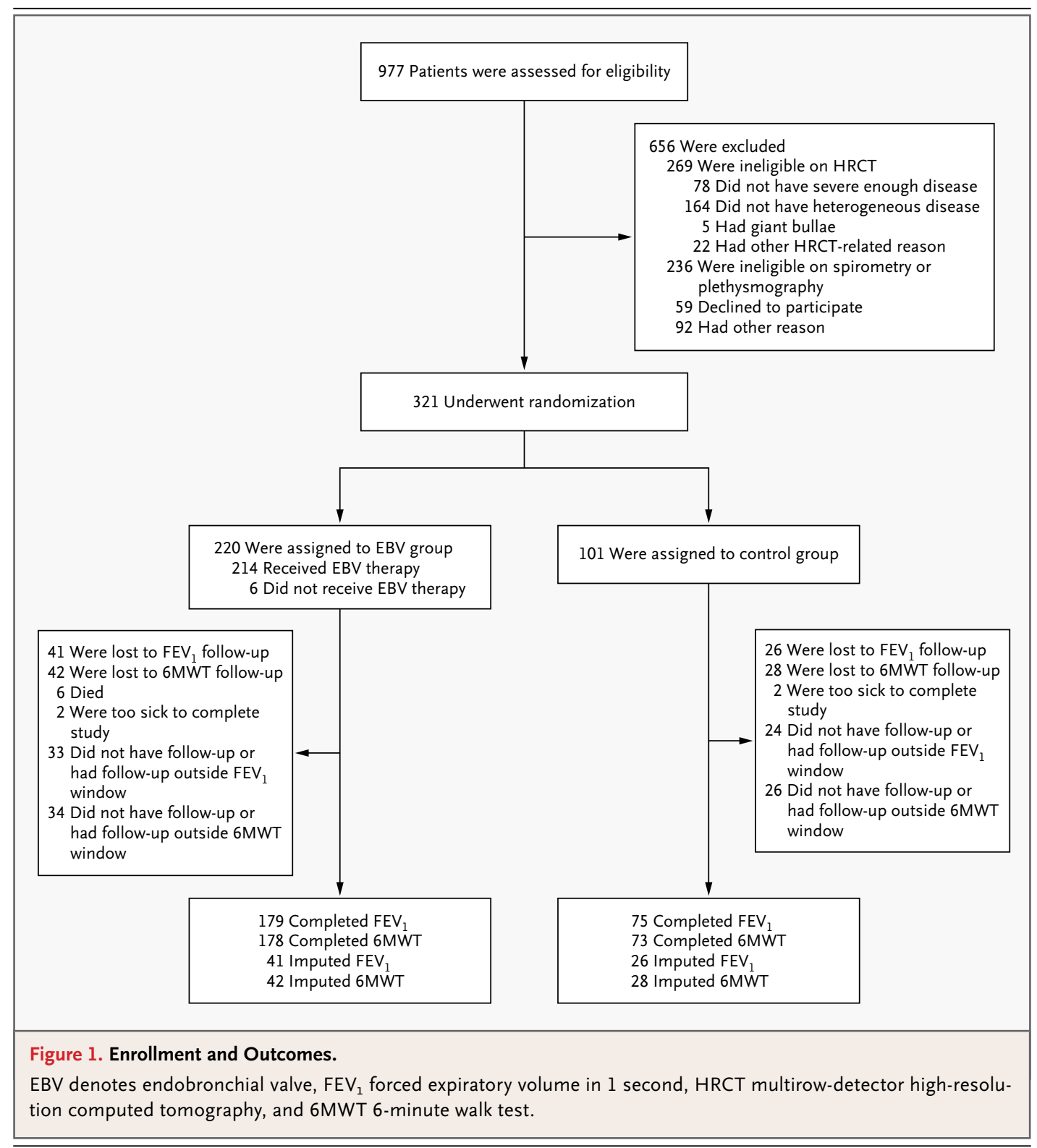

resolved with antibiotic therapy, with six patients requiring hospitalization and none requiring mechanical ventilation. The infections were resolved in six patients (at days 15, 163, 208, 230, 275 , and 356) without valve removal, and six patients underwent valve removal (at days 30, 208, and 258).

Table 3, and Table S3 in the Supplementary Appendix, list other important or serious adverse events in the early window after the procedure (within 90 days) and the late window (3 to 12 months). Hemoptysis (which was defined as bleeding requiring bronchoscopic inspection) during both the early and late windows was significantly increased in the EBV group $(5.6 \%$ of patients in the early window and $6.1 \%$ in the late window), as compared with no patients in the control group ( $\mathrm{P}=0.02$ for both comparisons); findings on bronchoscopy were most often the presence of oozing from granulation tissue. Pneumothorax occurred in $4.2 \%$ of patients in the EBV group (lasting longer than 7 days in 1.4\%) and in no patients in the control group during the early window $(\mathrm{P}=0.07)$ but was not more common in the EBV group (1.0\%) than in the control group (2.4\%) during the late window. Exacerbations of chronic obstructive pulmonary disease (COPD) requiring hospitalization in the 


\begin{tabular}{|c|c|c|c|c|}
\hline \multirow[t]{2}{*}{ Outcome } & $\begin{array}{l}\text { Endobronchial-Valve } \\
\text { Therapy }(\mathrm{N}=220)\end{array}$ & Control $(\mathrm{N}=101)$ & $\begin{array}{l}\text { Between-Group } \\
\text { Difference in Change } \\
\text { from Baseline }\end{array}$ & \multirow[t]{2}{*}{ P Value } \\
\hline & \multicolumn{3}{|c|}{ number ( $95 \%$ confidence interval) } & \\
\hline \multicolumn{5}{|l|}{ Primary outcome } \\
\hline \multicolumn{5}{|l|}{$\mathrm{FEV}_{1}$} \\
\hline Mean absolute percent change from baseline & 4.3 (1.4 to 7.2$)$ & $-2.5(-5.4$ to 0.4$)$ & 6.8 (2.1 to 11.5$)$ & 0.005 \\
\hline Mean change in value from baseline $-\mathrm{ml}$ & $34.5(10.8$ to 58.3$)$ & $-25.4(-48.3$ to -2.6$)$ & $60.0(21.5$ to 98.4$)$ & 0.002 \\
\hline $\begin{array}{l}\text { Mean absolute percent change in predicted value } \\
\text { from baseline }\end{array}$ & $1.0(0.2$ to 1.8$)$ & $-0.9(-1.7$ to -0.1$)$ & $1.9(0.5$ to 11.2$)$ & 0.007 \\
\hline \multicolumn{5}{|l|}{ Distance on 6-min walk test $\nmid$} \\
\hline Median absolute percent change from baseline & $2.5(-1.1$ to 6.1$)$ & $-3.2(-8.9$ to 2.4$)$ & $5.8(0.5$ to 11.2$)$ & 0.04 \\
\hline Median change from baseline $-m$ & $9.3(-0.5$ to 19.1$)$ & $-10.7(-29.6$ to 8.1$)$ & 19.1 (1.3 to 36.8$)$ & 0.02 \\
\hline \multicolumn{5}{|l|}{ Secondary outcome } \\
\hline Mean change in score on SGRQ from baselinet & $-2.8(-4.7$ to -1.0$)$ & $0.6(-1.8$ to 3.0$)$ & $-3.4(-6.7$ to 0.2$)$ & 0.04 \\
\hline $\begin{array}{l}\text { Mean change in score on Modified Medical Research } \\
\text { Council dyspnea scale from baseline } \mathbb{}\end{array}$ & $-0.1(-0.21$ to 0.09$)$ & $0.2(0.01$ to 0.37$)$ & $-0.3(-0.50$ to -0.01$)$ & 0.04 \\
\hline $\begin{array}{l}\text { Mean change in cycle ergometry peak workload from } \\
\text { baseline - W }\end{array}$ & $0.6(-1.5$ to 2.7$)$ & $-3.2(-4.5$ to -1.9$)$ & $3.8(0.1$ to 7.5$)$ & 0.05 \\
\hline $\begin{array}{l}\text { Median change in supplemental oxygen use from } \\
\text { baseline - liters/day } \uparrow\end{array}$ & $0.0(-117.3$ to 117.3$)$ & $0.0(-148.2$ to 148.2$)$ & -12.0 (-76.7 to 52.7$)$ & 0.005 \\
\hline \multicolumn{5}{|c|}{$\begin{array}{l}\text { For between-group mean differences, } 95 \% \text { confidence intervals and } \mathrm{P} \text { values were calculated with the use of a two-sided t-test. For between- } \\
\text { group median differences, values ware calculated with the use of a Hodges-Lehmann estimator with nonparametric } 95 \% \text { confidence inter- } \\
\text { vals, and } \mathrm{P} \text { values by means of a two-sided Wilcoxon rank-sum test. } \\
\text {-Values in this category were calculated in nonparametric analyses, so the imputed median shift is not the simple difference between the } \\
\text { treatment group and the control group. } \\
\text { Scores on the St. George's Respiratory Questionnaire (SGRQ) range from } 0 \text { to } 100 \text {, with higher scores indicating a worse quality of life. The } \\
\text { minimal clinically important difference is } 4 \text { points. } \\
\text { Scores on the Modified Medical Research Council dyspnea scale range from } 0 \text { to } 4 \text {, with higher scores indicating a greater severity of dys- } \\
\text { pnea. The minimal clinically important difference is } 1 \text { point. }\end{array}$} \\
\hline
\end{tabular}

early window occurred more commonly in the EBV group (7.9\%) than in the control group $(1.1 \%, \mathrm{P}=0.03)$ but occurred at a similar rate during the late window $(\mathrm{P}=0.84)$.

In 12 months of follow-up, valves were removed in 31 patients for reasons including retrieval of a migrated valve (in 8 patients), the patient's request for an unspecified reason (in 7), pneumonia management (in 3), placement in the incorrect lobe (in 3), COPD exacerbations (in 2), hemoptysis (in 1), and other reasons (in 7). Follow-up bronchoscopies, most often performed for valve removals or hemoptysis evaluation, were more frequent in the EBV group (23\%) than in the control group (1\%).

\section{PREDICTIVE CHARACTERISTICS}

Only heterogeneity (the difference in emphysema percentage between lobes in the treated lung) remained as an interaction in the multivariate mixed model for both $\mathrm{FEV}_{1}(\mathrm{P}=0.006)$ and distance on the 6 -minute walk test $(\mathrm{P}=0.01)$. The other interactions remaining in the models were fissure integrity for $\operatorname{FEV}_{1}(\mathrm{P}=0.01)$ and the ratio between $\mathrm{FEV}_{1}$ and the forced vital capacity (FVC) for the 6-minute walk test $(\mathrm{P}=0.03)$. Although these specific predictive variables were not explicitly prespecified, the multivariate mixedmodel approach from which these variables were defined was prespecified. The 15\% heterogeneity cutoff defining high or low heterogeneity status should be considered a post hoc analysis.

The enhancing effect of heterogeneity on changes in the $\mathrm{FEV}_{1}$ and the 6-minute walk test was significant within any quartile from the lower quartile to the upper quartile of baseline values and overall was greater with increasing magnitudes of heterogeneity (Fig. 2). At 6 months, on the basis of a cutoff at the median heterogeneity score of $15 \%$, the high-heterogeneity sub- 


\begin{tabular}{|c|c|c|c|}
\hline \multirow[t]{2}{*}{ Event } & $\begin{array}{l}\text { Endobronchial-Valve } \\
\text { Therapy }(\mathrm{N}=214)\end{array}$ & Control $(\mathrm{N}=87)$ & \multirow[t]{2}{*}{ P Value } \\
\hline & no. $(\%[95 \% \mathrm{CI}])$ & no. (\% [95\% CI]) & \\
\hline $\begin{array}{l}\text { Patients with any event in the composite of major } \\
\text { complications }\end{array}$ & $9(4.2[1.9-7.8])$ & $0(0[0.0-4.2])$ & 0.06 \\
\hline Death & $2(0.9[0.1-3.3])$ & $0(0[0.0-4.2])$ & 1.00 \\
\hline \multicolumn{4}{|l|}{ Cardiovascular event } \\
\hline Arrhythmia & $2(0.9[0.1-3.3])$ & $0(0[0.0-4.2])$ & 1.00 \\
\hline Congestive heart failure & $0(0[0.0-1.1])$ & $1(1.1[0.0-6.2])$ & 0.29 \\
\hline Coronary artery disease & $2(0.9[0.1-3.3])$ & $1(1.1[0.0-6.2])$ & 1.00 \\
\hline \multicolumn{4}{|l|}{ Pulmonary or thoracic event } \\
\hline \multicolumn{4}{|l|}{ COPD exacerbation } \\
\hline With hospitalization & $17(7.9[4.7-12.4])$ & $1(1.1[0.0-6.2])$ & 0.03 \\
\hline Without hospitalization & $3(1.4[0.3-4.0])$ & $0(0[0.0-4.2])$ & 0.56 \\
\hline Pulmonary infection & $4(1.9[0.5-4.7])$ & $0(0[0.0-4.2])$ & 0.33 \\
\hline Respiratory failure & $3(1.4[0.3-4.0])$ & $0(0[0.0-4.2])$ & 0.56 \\
\hline \multicolumn{4}{|l|}{ Pneumonia } \\
\hline Not distal to valve & $5(2.3[0.8-5.4])$ & $2(2.3[0.3-8.1])$ & 1.00 \\
\hline Distal to valve & $2(0.9[0.1-3.3])$ & NA & NA \\
\hline New or worsening hypercapnia』 & $2(0.9[0.1-3.3])$ & $0(0[0.0-4.2])$ & 1.00 \\
\hline Hypoxemia & $3(1.4[0.3-4.0])$ & $0(0[0.0-4.2])$ & 0.56 \\
\hline \multicolumn{4}{|l|}{ Hemoptysis } \\
\hline Massive & $1(0.5[0.0-2.6])$ & $0(0[0.0-4.2])$ & 1.00 \\
\hline Any & $12(5.6[2.9-9.6])$ & $0(0[0.0-4.2])$ & 0.02 \\
\hline \multicolumn{4}{|l|}{ Pneumothorax or air leak } \\
\hline Duration of $>7$ days & $3(1.4[0.3-4.0])$ & $0(0[0.0-4.2])$ & 0.56 \\
\hline Expanding & $3(1.4[0.3-4.0])$ & $0(0[0.0-4.2])$ & 0.56 \\
\hline Stable & $3(1.4[0.3-4.0])$ & $0(0[0.0-4.2])$ & 0.56 \\
\hline Empyemałr & $0(0[0.0-1.7])$ & $0(0[0.0-4.2])$ & NA \\
\hline Noncardiac chest pain & $1(0.5[0.0-2.6])$ & $0(0[0.0-4.2])$ & 1.00 \\
\hline \multicolumn{4}{|l|}{ Implant-related event } \\
\hline Valve expectoration, aspiration, or migration & $10(4.7[2.3-8.4])$ & NA & NA \\
\hline Formation of bronchial granulation tissue & $5(2.3[0.8-5.4])$ & NA & NA \\
\hline Bronchial trauma & $1(0.5[0.0-2.6])$ & NA & NA \\
\hline
\end{tabular}

* Adverse events were evaluated in the safety population, which consisted of 214 patients receiving endobronchial-valve therapy and 87 patients in the control group. The composite of six major complications consisted of death, empyema, massive hemoptysis, pneumonia distal to the implanted valves, pneumothorax or prolonged air leak, or respiratory failure. For a complete list of adverse events, see Table S1 in the Supplementary Appendix. NA denotes not applicable. $\uparrow P$ values were calculated with the use of a two-sided Fisher's exact test.

$T$ This adverse event was included in the composite of six major complications.

$\int \mathrm{New}$ or worsening hypercapnia was defined as a partial pressure of carbon dioxide of more than $45 \mathrm{~mm} \mathrm{Hg}$ and an increase of more than $10 \mathrm{~mm} \mathrm{Hg}$ above baseline.

group had greater relative improvements in both the $\mathrm{FEV}_{1}(10.7 \%, \mathrm{P}=0.004)$ and the 6-minute walk test $(12.4 \%, \mathrm{P}=0.002)$ (Table 4$)$.

Patients in the EBV group who had complete fissures had incremental improvements in the $\mathrm{FEV}_{1}$ of $16.2 \%$ at 6 months and $17.9 \%$ at 12 months ( $\mathrm{P}<0.001$ for both comparisons) in contrast to insignificant changes of $2.0 \%$ and $2.8 \%$, 


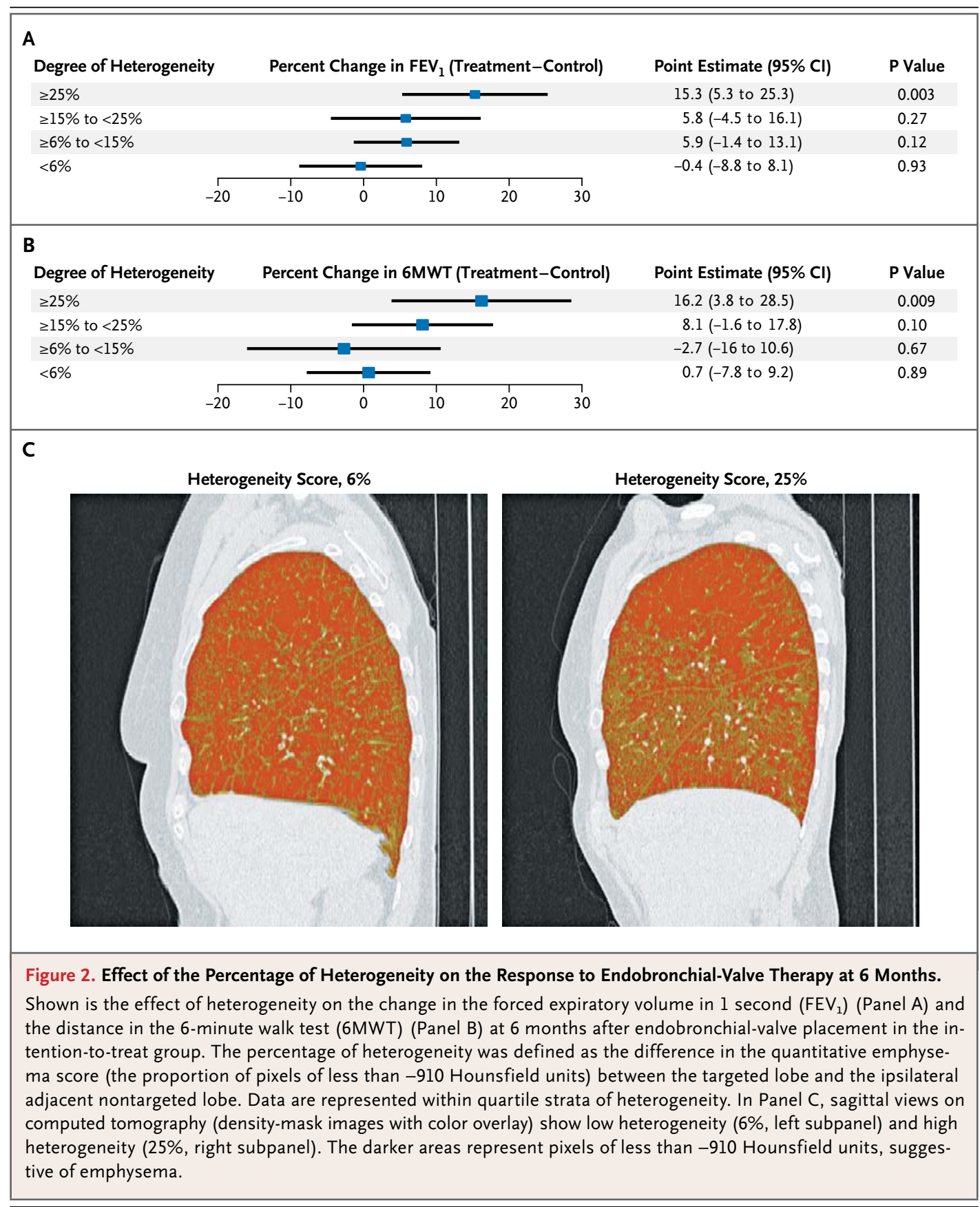

respectively, in the group with incomplete fissures, although the between-group difference on the 6-minute walk test was not significant at 6 or 12 months in either group (Table 4).

\section{QUANTITATIVE HRCT LOBAR VOLUME REDISTRIBUTION AND ASSOCIATION WITH LUNG FUNCTION}

Among patients in the EBV group, there was a greater reduction in the HRCT-evaluated volume of the target lobe at 6 months $(378.4 \mathrm{ml})$ than in the control group (16.3 ml, $\mathrm{P}<0.002)$, an effect that was enhanced in the subgroup with complete fissures (a reduction of $712.5 \mathrm{ml}$ in the EBV group vs. an increase of $2.2 \mathrm{ml}$ in the control group, $\mathrm{P}<0.001$ ) (Fig. S3A in the Supplementary Appendix). Expansion in the volume of the adjacent nontargeted lobes occurred in patients in the EBV group, as compared with that in the control group, an effect that was enhanced with complete fissures $(\mathrm{P}<0.002$ for both comparisons). 


\begin{tabular}{|c|c|c|c|c|}
\hline \multirow[t]{3}{*}{ Subgroup and Outcome } & \multicolumn{2}{|c|}{$\begin{array}{l}\text { Percent Change from Baseline } \\
\text { at } 6 \text { Mo }\end{array}$} & \multicolumn{2}{|c|}{$\begin{array}{l}\text { Percent Change from Baseline } \\
\text { at } 12 \mathrm{Mo}\end{array}$} \\
\hline & $\begin{array}{c}\text { Difference between EBV } \\
\text { Group and Control } \\
\text { Group }\end{array}$ & P Value $†$ & $\begin{array}{l}\text { Difference between EBV } \\
\text { Group and Control } \\
\text { Group }\end{array}$ & P Value \\
\hline & $\%(95 \% \mathrm{Cl})$ & & $\%(95 \% \mathrm{Cl})$ & \\
\hline \multicolumn{5}{|l|}{ High heterogeneity } \\
\hline $\mathrm{FEV}_{1}$ & 10.7 (3.5 to 17.9$)$ & 0.004 & 13.3 (5.7 to 20.9$)$ & $<0.001$ \\
\hline Distance on 6-min walk test & 12.4 (4.8 to 20.1$)$ & 0.002 & 7.1 (-0.8 to 14.9$)$ & 0.08 \\
\hline \multicolumn{5}{|l|}{ Low heterogeneity } \\
\hline $\mathrm{FEV}_{1}$ & $2.5(-3.1$ to 8.2$)$ & 0.38 & $1.5(-4.7$ to 7.6$)$ & 0.64 \\
\hline Distance on 6-min walk test & $-1.0(-6.4$ to 8.4$)$ & 0.80 & $-0.6(-6.4$ to 7.7$)$ & 0.84 \\
\hline \multicolumn{5}{|l|}{ Complete fissure } \\
\hline $\mathrm{FEV}_{1}$ & 16.2 (8.8 to 23.8$)$ & $<0.001$ & 17.9 (9.8 to 25.9 ) & $<0.001$ \\
\hline Distance on 6-min walk test & 7.7 (-1.8 to 17.2$)$ & 0.14 & $3.9(-4.0$ to 11.8$)$ & 0.31 \\
\hline \multicolumn{5}{|l|}{ Incomplete fissure } \\
\hline $\mathrm{FEV}_{1}$ & $2.0(-3.9$ to 7.9$)$ & 0.51 & $2.8(-3.8$ to 9.4$)$ & 0.41 \\
\hline Distance on 6-min walk test & $5.3(-1.5$ to 12.2$)$ & 0.13 & $4.5(-2.7$ to 11.8$)$ & 0.20 \\
\hline
\end{tabular}

The change in the target-lobe volume was inversely correlated with the change in the $\mathrm{FEV}_{1}$ $(\mathrm{R}=-0.53, \mathrm{P}<0.001)$ (Fig. S3B in the Supplementary Appendix).

VALVE REMOVAL, MIGRATION, AND POSITIONING Post-procedure bronchoscopic valve removal was successfully performed in 85 of 87 attempts $(97.7 \%$ ) in 31 subjects (range, 1 to 377 days after insertion). Valve removal was based on investigators' judgment and not specific protocol criteria. Investigators determined that the valves needed to be removed because of valve migration (in 8 patients), patient's request for an unspecified reason (in 7), pneumonia distal to valves (in 3), placement in the incorrect lobe (in 3), COPD exacerbation (in 2), hemoptysis (in 1), and other reasons (in 7) (Table S6 in the Supplementary Appendix). Notably, 85 of 194 patients who could be evaluated on HRCT at 6 months $(43.8 \%)$ were found to have incomplete lobar isolation; in 67 patients (34.5\%), the findings were unexpected and due to valve positioning. Patients with confirmed complete lobar isolation had significantly greater improvements in the $\mathrm{FEV}_{1}$ and distance on the 6-minute walk test than those with incomplete lobar isolation (Table S7 in the Supplementary Appendix).

\section{COMPLICATIONS AFTER STUDY COMPLETION}

Since trial completion in 2007, investigators have reported that 8 of 214 patients underwent elective removal of valves associated with adverse events (range, 12 to 41 months after the procedure) and 3 other patients had spontaneous expectoration of a valve (Table S6 in the Supplementary Appendix). Investigators have reported 6 deaths (none of them device-related) after completion of the trial (4 in the EBV group and 2 in the control group).

\section{DISCUSSION}

We found that unilobar placement of endobronchial valves has a modest positive effect on expiratory flow rates and distance on the 6-minute walk test. This improvement comes at a cost of more frequent hemoptysis and COPD exacerbations in the few months after valve implantation in patients with advanced, hyperinflated emphy- 
sema. Overall, there were modest improvements in quality of life, dyspnea, incremental exercise response, and supplemental oxygen use. Although the overall magnitude of effect was modest, high values for disease heterogeneity and fissure integrity on CT imaging were more common in patients who had a clinically important response. The dominant adverse event driving a quantitative increase in the rate of adverse events in the EBV group versus the control group was the $4.2 \%$ incidence of pneumonia distal to the valves, confirming previous reports..$^{5,6,9,11-13}$ Other adverse events, which were increased in the periprocedural period after valve placement, included an increased rate of COPD exacerbations requiring hospitalization, pneumothorax, and hemoptysis related to oozing from granulation tissue.

Similar to lung-volume-reduction surgery, endobronchial-valve therapy is associated with improvements in lung function and with clinical benefits that are greatest in the presence of heterogeneous lung involvement. After reduction of the most severely diseased lung units, expansion of the more viable, less emphysematous nontreated lung results in substantial improvements in lung mechanics. ${ }^{2,6,10,24,25}$ Among patients who received endobronchial-valve therapy, those in the high-heterogeneity subgroup had greater improvements in both the $\mathrm{FEV}_{1}$ and distance on the 6-minute walk test than did patients with lower heterogeneity. This greater response in the high-heterogeneity subgroup supports the use of quantitative HRCT as an important tool in optimizing the selection of patients for endobronchial-valve therapy.

CT fissure completeness on HRCT was analyzed as a surrogate for interlobar collaterals, a feature postulated to mitigate the beneficial effects of lobar isolation by means of endobronchial-valve therapy. ${ }^{9,26-34}$ We confirmed that fissure completeness was associated with improvement in $\mathrm{FEV}_{1}$ (Table 4) and the magnitude of change in the lobar volume (Fig. S3 in the Sup- plementary Appendix). The magnitude of this association was strengthened when valves were properly positioned to effect complete lobar isolation. Thus, we speculate that future strategies that are directed at the selection of patients or targeting of lobes to minimize collateral ventilation and to optimize valve positioning to isolate the lobe should further improve the clinical response to endobronchial-valve therapy.

We document a reduction in the volume of the target lobe that was associated with both volume expansion in the less diseased adjacent lobe as well as improvement in $\mathrm{FEV}_{1}$ (Fig. $\mathrm{S} 3$ in the Supplementary Appendix). These data thus support mechanisms underlying the physiological and functional improvements seen with endobronchial-valve therapy that are consistent with those previously identified with lung-volume-reduction surgery and preliminary reports on endobronchial-valve therapy. ${ }^{9,35-39}$ During the study, both patients and investigators were unaware of the association between clinical outcome measures and changes in quantitative CT measures, which adds further validity to our results in the absence of study-group blinding.

In conclusion, unilateral lobar treatment with endobronchial valves resulted in modest improvements in lung function, exercise tolerance, and symptoms in patients with advanced heterogeneous emphysema. These benefits came at a cost of more frequent hemoptysis and COPD exacerbations in the months after valve implantation. Greater heterogeneity of emphysema between lobes and intact interlobar fissures appear to identify patients with a greater likelihood of clinically important functional and physiological responses to endobronchial-valve therapy, but this difference needs to be confirmed in welldesigned clinical trials.

Supported by Emphasys Medical (now Pulmonx) and a grant (1 P50HL084948, to Dr. Sciurba) from the National Institutes of Health.

Disclosure forms provided by the authors are available with the full text of this article at NEJM.org.

\section{REFERENCES}

1. Criner GJ, Cordova FC, Furukawa S, et al. Prospective randomized trial comparing bilateral lung volume reduction surgery to pulmonary rehabilitation in severe chronic obstructive pulmonary disease. Am J Respir Crit Care Med 1999;160:2018-27.

2. Fishman A, Martinez F, Naunheim K, et al. A randomized trial comparing lung- volume-reduction surgery with medical therapy for severe emphysema. N Engl J Med 2003;348:2059-73.

3. Naunheim KS, Wood DE, Krasna MJ, et al. Predictors of operative mortality and cardiopulmonary morbidity in the $\mathrm{Na}$ tional Emphysema Treatment Trial. J Thorac Cardiovasc Surg 2006;131:43-53.
4. Naunheim KS. Lung-volume reduction surgery: a vanishing operation? J Thorac Cardiovasc Surg 2007;133:1412-3.

5. Wan IY, Toma TP, Geddes DM, et al. Bronchoscopic lung volume reduction for end-stage emphysema: report on the first 98 patients. Chest 2006;129:518-26.

6. Wood DE, McKenna RJ Jr, Yusen RD, 
et al. A multicenter trial of an intrabronchial valve for treatment of severe emphysema. J Thorac Cardiovasc Surg 2007; 133:65-73.

7. Reilly J, Washko G, Pinto-Plata V, et al. Biological lung volume reduction: a new bronchoscopic therapy for advanced emphysema. Chest 2007;131:1108-13.

8. Choong CK, Macklem PT, Pierce JA, et al. Airway bypass improves the mechanical properties of explanted emphysematous lungs. Am J Respir Crit Care Med 2008;178:902-5.

9. Hopkinson NS, Toma TP, Hansell $\mathrm{DM}$, et al. Effect of bronchoscopic lung volume reduction on dynamic hyperinflation and exercise in emphysema. Am J Respir Crit Care Med 2005;171:453-60.

10. Fessler HE, Scharf SM, Ingenito EP, McKenna RJ Jr, Sharafkhaneh A. Physiologic basis for improved pulmonary function after lung volume reduction. Proc Am Thorac Soc 2008;5:416-20.

11. Snell GI, Holsworth L, Borrill ZL, et al. The potential for bronchoscopic lung volume reduction using bronchial prostheses: a pilot study. Chest 2003;124:1073-80.

12. Toma TP, Hopkinson NS, Polkey MI, Geddes DM. Endobronchial volume reduction: a myth or a marvel? Semin Respir Crit Care Med 2004;25:399-404.

13. Venuta F, de Giacomo T, Rendina EA, et al. Bronchoscopic lung-volume reduction with one-way valves in patients with heterogenous emphysema. Ann Thorac Surg 2005;79:411-6.

14. Strange C, Herth FJ, Kovitz KL, et al. Design of the Endobronchial Valve for Emphysema Palliation Trial (VENT): a non-surgical method of lung volume reduction. BMC Pulm Med 2007;7:10.

15. Brown MS, McNitt-Gray MF, Mankovich NJ, et al. Method for segmenting chest CT image data using an anatomical model: preliminary results. IEEE Trans Med Imaging 1997;16:828-39.

16. Brown MS, McNitt-Gray MF, Pais R, et al. CAD in clinical trials: current role and architectural requirements. Comput Med Imaging Graph 2007;31:332-7.

17. Brown MS, Wilson LS, Doust BD, Gill
RW, Sun C. Knowledge-based method for segmentation and analysis of lung boundaries in chest X-ray images. Comput Med Imaging Graph 1998;22:463-77.

18. Freeman TB, Vawter DE, Leaverton $\mathrm{PE}$, et al. Use of placebo surgery in controlled trials of a cellular-based therapy for Parkinson's disease. N Engl J Med 1999;341:988-92.

19. McCulloch P, Taylor I, Sasako M Lovett B, Griffin D. Randomised trials in surgery: problems and possible solutions. BMJ 2002;324:1448-51.

20. Piantadosi S. Why trials have not been used extensively in surgery. In: Piantados S, ed. Clinical trials: a methodologic perspective. 2nd ed. Hoboken, NJ: John Wiley, 2005:90-2.

21. Müller NL, Staples CA, Miller RR, Abboud RT. "Density mask": an objective method to quantitate emphysema using computed tomography. Chest 1988;94 782-7.

22. Wang R, Lagakos SW, Ware JH, Hunter DJ, Drazen JM. Statistics in medicine reporting of subgroup analyses in clinical trials. N Engl J Med 2007;357:2189-94.

23. Multiple comparisons. In: van Belle GFL, Heagerty PJ, Lumley T. Biostatistics, a methodology for the health sciences. 2nd ed. Hoboken, NJ: John Wiley, 2004:540.

24. Rogers RM, Coxson HO, Sciurba FC Keenan RJ, Whittall KP, Hogg JC. Preoperative severity of emphysema predictive of improvement after lung volume reduction surgery: use of CT morphometry. Chest 2000;118:1240-7.

25. McKenna RJ Jr, Brenner M, Fischel RJ, et al. Patient selection criteria for lung volume reduction surgery. J Thorac Cardiovasc Surg 1997;114:957-64.

26. Salanitri J, Kalff V, Kelly M, Holsworth L, Williams T, Snell G. 133Xenon ventilation scintigraphy applied to bronchoscopic lung volume reduction techniques for emphysema: relevance of interlobar collaterals. Intern Med J 2005;35 97-103.

27. Fessler HE. Collateral ventilation, the bane of bronchoscopic volume reduction. Am J Respir Crit Care Med 2005;171:423-4.
28. Kent EM, Blades B. The surgical anatomy of the pulmonary lobes. J Thorac Surg 1942;12:18-30.

29. Bergman RA, Afifi AK, Miyauchi R. Lungs and trachea. In: Bergman RA, ed. Illustrated encyclopedia of human anatomic variation: Opus IV: organ systems: respiratory system. Anatomy Atlases, 2008. (Accessed August 30, 2010, at http://www .anatomyatlases.org/AnatomicVariants/ OrganSystem/Text/LungsTrachea.shtml.) 30. Lukose R, Paul S, Sunitha DM, et al. Morphology of the lungs: variations in the lobes and fissures. Biomedicine 1999;19: 227-32.

31. Cetti EJ, Moore AJ, Geddes DM. Collateral ventilation. Thorax 2006;61:371-3. 32. Hogg JC, Macklem PT, Thurlbeck WM. The resistance of collateral channels in excised human lungs. J Clin Invest 1969; 48:421-31.

33. Terry PB, Traystman RJ, Newball HH, Batra G, Menkes HA. Collateral ventilation in man. N Engl J Med 1978;298:10-5.

34. Macklem PT. Collateral ventilation. N Engl J Med 1978;298:49-50.

35. Sciurba FC, Rogers RM, Keenan RJ, et al. Improvement in pulmonary function and elastic recoil after lung-reduction surgery for diffuse emphysema. $\mathrm{N}$ Engl J Med 1996;334:1095-9.

36. Gelb AF, Zamel N, McKenna RJ Jr, Brenner M. Mechanism of short-term improvement in lung function after emphysema resection. Am J Respir Crit Care Med 1996;154:945-51.

37. Ingenito EP, Evans RB, Loring SH, et al. Relation between preoperative inspiratory lung resistance and the outcome of lung-volume-reduction surgery for emphysema. N Engl J Med 1998;338:1181-5. 38. Fessler HE, Permutt S. Lung volume reduction surgery and airflow limitation. Am J Respir Crit Care Med 1998;157:71522.

39. McKenna RJ Jr, Brenner M, Fischel RJ, Gelb AF. Should lung volume reduction for emphysema be unilateral or bilateral? J Thorac Cardiovasc Surg 1996;112:13318.

Copyright (c) 2010 Massachusetts Medical Society 